Check for updates

Cite this: RSC Adv., 2019, 9, 21539

Received 26th March 2019

Accepted 19th June 2019

DOI: 10.1039/c9ra02308a

rsc.li/rsc-advances

\section{Polymer of intrinsic microporosity-based macroporous membrane with high thermal stability as a Li-ion battery separator}

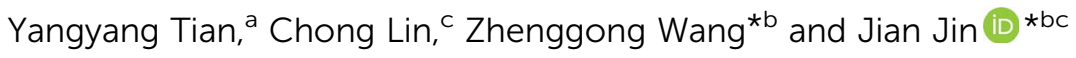 \\ Polymers of intrinsic microporosity (PIMs) have numerous advantages such as good thermal stability $\left(T_{\mathrm{g}}>\right.$ \\ $300^{\circ} \mathrm{C}$ ) and mechanical stability (tensile strength at break $>60 \mathrm{MPa}$ ) as well as excellent electrical insulation \\ performance and chemical/electrochemical stability. Herein, a macroporous membrane made up of \\ a polymer of intrinsic microporosity (PIM-1) was fabricated and used as a separator of a rechargeable Li- \\ ion battery for the first time. The PIM-1-based separator showed good thermal resistance with $T_{\mathrm{g}}>$ \\ $300^{\circ} \mathrm{C}$, high electrolyte uptake, and excellent Li-ion conductivity.
}

\section{Introduction}

As one of the most attractive energy storage systems, the Li-ion battery has received considerable attention due to the properties of high energy density, long cycle life, no memory effect, and low self-discharging. ${ }^{\mathbf{1 - 4}}$ As an important part of a Li-ion battery, the separator plays an essential function in preventing the physical contact between the cathode and anode while absorbing the electrolyte for ion transportation., ${ }^{5,6}$ The safety of a Li-ion battery is closely related to the separator because the temperature of the whole battery will increase dramatically during the process of high rate charge/discharge, leading to the abuse of the battery. ${ }^{7-11}$ Sometimes, the onset temperature of a Li-ion battery can be as high as $200{ }^{\circ} \mathrm{C} .{ }^{\mathbf{1 3 , 1 4}}$ An ideal separator should be thermally stable enough to separate the two electrodes. Up to now, the commercial separators mainly include polyolefins such as polyethylene (PE), polypropylene (PP), or their combination. ${ }^{12}$ The melting temperatures of these separators are usually in the range from $135{ }^{\circ} \mathrm{C}$ to $165{ }^{\circ} \mathrm{C}$, thereby suffering from severe shrinkage with increasing temperature, which may cause a battery short circuit and even explosion. Moreover, the poor electrolyte wettability of the polyolefinbased separators restrains the exhibition of a battery charge/ discharge performance and increases the manufacturing cost. ${ }^{15}$ Thus, thermal stability and electrolyte wettability are two

${ }^{a}$ School of Nano Technology and Nano Bionics, University of Science and Technology of China, Hefei 230026, China

${ }^{b}$ College of Chemistry, Chemical Engineering and Materials Science, Soochow University, Suzhou 215123, China.E-mail: jjin2009@sinano.ac.cn; zgwang2017@ suda.edu.cn

${ }^{c} i$-Lab, Suzhou Institute of Nano-Tech and Nano-Bionics, Chinese Academy of Sciences, Suzhou 215123, China

† Electronic supplementary information (ESI) available. See DOI: 10.1039/c9ra02308a important parameters to evaluate a separator for the development of a high-performance Li-ion battery.

Various polymers such as poly(vinylidene fluoride) (PVDF), polyacrylonitrile (PAN), poly(methyl methacrylate) (PMMA), polyetherimide (PEI), and polyimide (PI) have been investigated for use as Li-ion battery separators to overcome the drawbacks of polyolefins. ${ }^{16-23}$ Previous results have shown that these polymers can be better separators in consideration of both the thermal stability and/or electrolyte wettability. In the past decade, the polymers of intrinsic microporosity (PIMs) have aroused great attention due to their excellent performance for gas separation. PIMs possess an intrinsic microporous structure with pore size $<2 \mathrm{~nm}$ and high surface area $\left(600-1000 \mathrm{~m}^{2}\right.$ $\left.\mathrm{g}^{-1}\right)$. They demonstrate ultra-high gas permeability, representing the best comprehensive separation performance among those of the polymer materials. ${ }^{\mathbf{2 4 , 2 5}}$ Besides, PIM membranes for dye adsorption and separation, organic solvent nanofiltration, and enantiomer separation were also studied. ${ }^{26-28}$ A recent study revealed that dense PIM membranes can block polysulfides in a Li-S battery owing to their abundant sub-nm pores. However, they are not feasible to be used as a Li-ion battery separator because the $\mathrm{Li}^{+}$conductivity of the dense PIM membranes is very low. ${ }^{29}$ In fact, as newly developed polymers, PIMs have many advantages such as good thermal stability $\left(T_{\mathrm{g}}>300{ }^{\circ} \mathrm{C}\right)$ and mechanical stability (tensile strength at break $>60 \mathrm{MPa}$ ) as well as excellent electrical insulation performance and chemical/electrochemical stability. These merits meet the fundamental requirements for battery separators. Meanwhile, the existence of polar ether bonds in the dibenzodioxin linkage and -CN groups in some PIMs can enhance the interaction between the electrolyte and the separator, thus improving the $\mathrm{Li}^{+}$ion transportation across the separator.

In this work, we reported the first attempt to use a PIM-1 membrane, which is a representative polymer of PIMs, as a Liion battery separator. To achieve this goal, a PIM-1/SiO 
(named PIM-1/S) composite separator was first fabricated via a nanoparticle-assisted dry phase transition method. A series of electrochemical tests revealed that the PIM-1/S separator possessed higher $\mathrm{Li}^{+}$conductivity and improved charge/ discharge battery performance. Importantly, the PIM-1/S separator showed excellent thermal stability and better discharge performance at high temperatures.

\section{Experimental}

\section{Materials}

3,4-Dimethoxyaniline (98\%), boron tribromide $\left(\mathrm{BBr}_{3}, 99.9 \%\right)$, anhydrous toluene (99.8\%), tetrafluoroterephthalonitrile (TFTPN), and dimethylacetamide (DMAc, 99\%) were obtained from Sigma-Aldrich and used as received. $\mathrm{SiO}_{2}$ nanoparticles $(14 \mathrm{~nm})(\mathrm{S} 5505$ Silica, powder $0.014 \mu \mathrm{m})$ were purchased from Sigma-Aldrich. Anhydrous potassium carbonate $\left(\mathrm{K}_{2} \mathrm{CO}_{3}, 99.9 \%\right)$ was purchased from Sinopharm Chemical Reagent Co., Ltd and used as received. 5,5',6,6'-Tetrahydroxy-3,3,3', $3^{\prime}$-tetramethylspirobisindane (TTSBI, 97\%) purchased from Alfa Aesar was purified by crystallization from a mixed solvent of methanol and dichloromethane. Aluminum foil, electrolyte, 2032-coin cell cases were purchased from Land Electronic., Ltd, China.

\section{Instruments and characterization}

SEM was performed on a Quanta 400 FEG field-emission scanning electron microscope. TEM was conducted on a Tecnai G2 F20 S-Twin field-emission transmission electron microscope. XRD was performed on Bruker D8. FTIR spectroscopy was performed using a Thermo FTIR spectrometer. TG analysis was performed using TG/DTA 6200. Electrochemical measurements were carried out using Land battery analyzers. The Accelerated Surface Area and Porosimetry (ASAP) 2020 system (Micromeritics Instrument Corporation) was used to carry out the experiment for studying $\mathrm{N}_{2}$ adsorption/desorption of the powder samples. Molecular weights and polydispersity index (PDI) were determined by Varian (PL-GPC 50) gel permeation chromatography (GPC) using ultrastyragel columns and THF as an eluent at a flow rate of $1 \mathrm{ml} \mathrm{min}^{-1}$ at $40{ }^{\circ} \mathrm{C}$. The values were determined by comparison with a series of polystyrene standards.

\section{Electrochemical measurement}

To test the battery performance, 2032-type coin cells made up of $\mathrm{LiFePO}_{4}$ were used as the cathode, PIM-1/S or Celgard 2400 was employed as a separator, and a Li metal foil was utilized as the counter electrode. The electrolyte consisted of $1 \mathrm{M} \mathrm{LiPF}_{6}$ in a mixture of ethyl methyl carbonate (EMC), ethylene carbonate (EC), and dimethyl carbonate (DMC). The coin cells were assembled in an argon-filled glove box. The working electrodes were cycled between $2.5 \mathrm{~V}$ and $4.2 \mathrm{~V} v s . \mathrm{Li}^{+} / \mathrm{Li}$. Electrochemical impedance spectroscopy (EIS) was performed on an Auto-lab electrochemical work station over the frequency range from $100 \mathrm{kHz}$ to $10 \mathrm{MHz}$.

\section{Synthesis of PIM-1}

Under a nitrogen atmosphere, $3.001 \mathrm{~g}$ (15 mmol) of tetrafluoroterephthalonitrile (TFTPN) and $5.106 \mathrm{~g}(15 \mathrm{mmol})$ of $5,5^{\prime}, 6,6^{\prime}$-tetrahydroxy-3,3,3', $3^{\prime}$-tetramethylspirobisindane (TTSBI) were dissolved in $25 \mathrm{ml}$ anhydrous DMAc. Then, $6.21 \mathrm{~g}$ (45 $\mathrm{mmol})$ of anhydrous milled $\mathrm{K}_{2} \mathrm{CO}_{3}$ was further added. Then, the flask was transferred to an oil bath at $160{ }^{\circ} \mathrm{C}$ under mechanical stirring. About $3 \mathrm{~min}$ later, a viscous yellow solution was formed and $20 \mathrm{ml}$ toluene was added. Several minutes later, $20 \mathrm{ml}$ toluene was further added to dilute the solution. Then, the mixture was poured into $300 \mathrm{ml}$ methanol, and an elastic thread-like lightyellow polymer was observed. The polymer product was dissolved in chloroform and re-precipitated in methanol. The procedure was repeated for two times. The resulting polymer was boiled in Milli-Q water for $4-5 \mathrm{~h}$ and dried at $80^{\circ} \mathrm{C}$ under vacuum for $48 \mathrm{~h} .{ }^{1} \mathrm{H}$ NMR (400 MHz, $\mathrm{CDCl}_{3}-d$ ) $\delta: 1.2-1.4$ (br. m, $12 \mathrm{H}, \mathrm{CH}_{3}$ ), 2.1-2.4 (br. m, 4H, $\mathrm{CH}_{2}$ ), 6.4 (br. s, $2 \mathrm{H}, \mathrm{CH}$ ), 6.8 (br. s, $2 \mathrm{H}, \mathrm{CH}$ ). BET surface area: $720 \mathrm{~m}^{2} \mathrm{~g}^{-1}$. Molecular weight: $M_{\mathrm{W}}=140000 \mathrm{~g}$ $\mathrm{mol}^{-1}, M_{\mathrm{n}}=80000 \mathrm{~g} \mathrm{~mol}^{-1}$.

\section{Preparation of PIM-1/S separator}

First, $300 \mathrm{mg}$ of PIM-1 was dissolved in $3 \mathrm{ml}$ chloroform. Then, $50 \mathrm{mg}$ of commercial silica nanoparticles and $500 \mu \mathrm{l}$ of butanol were added into the above solvent. The mixture was subjected to continuous stirring for 1 day and sonicated for 1 hour. Then, the dispersion was casted on a glass board and dried at room temperature for 2 hours. Finally, it was completely dried under vacuum at $80{ }^{\circ} \mathrm{C}$ for 1 day.

\section{Results and discussion}

PIM-1 was synthesized via a one-step polycondensation reaction based on double-aromatic nucleophilic substitution using a previously reported method (Fig. S1 $\dagger$ ). ${ }^{30}$ Fig. 1a shows the chemical structure of PIM-1, which was confirmed by ${ }^{1} \mathrm{H}$ NMR and ATR-FTIR spectra (Fig. S2 and S3†). Due to the rigid ladderlike chain structure, PIM-1 could be dissolved only in solvents having low boiling points such as $\mathrm{CHCl}_{3}$ and THF. However, it tended to form a dense membrane when the low-boiling-point solvents were used as the solvents of the doping solution. This dense membrane was not applicable for the Li-ion battery separator because $\mathrm{Li}^{+}$transport was blocked. To solve this problem, we adopted a nanoparticle-assisted phase inversion method to obtain a PIM-1-based macroporous membrane, where $n$-butyl alcohol and $\mathrm{SiO}_{2}$ nanoparticles were added into the PIM-1 doping solution to assist the construction of macropores (please see ESI† for detailed description and discussion). ${ }^{31,32}$ Fig. $1 \mathrm{~b}$ shows the digital photo of the resulting yellow membrane, which is non-transparent and flexible. The porosity of the PIM-1/S membrane was calculated to be $75 \%$ based on the isobutyl alcohol uptake (please see $\mathrm{ESI}_{\dagger} \dagger$ for detailed description). This value was almost twice that of the PP separator (about 37\%). The SEM images shown in Fig. 1c-e demonstrate the macroporous structure of the PIM-1/S separator. Fig. 1d and e display the SEM images of the air and bottom surfaces of the membrane, respectively, indicating 
$\mathbf{a}$
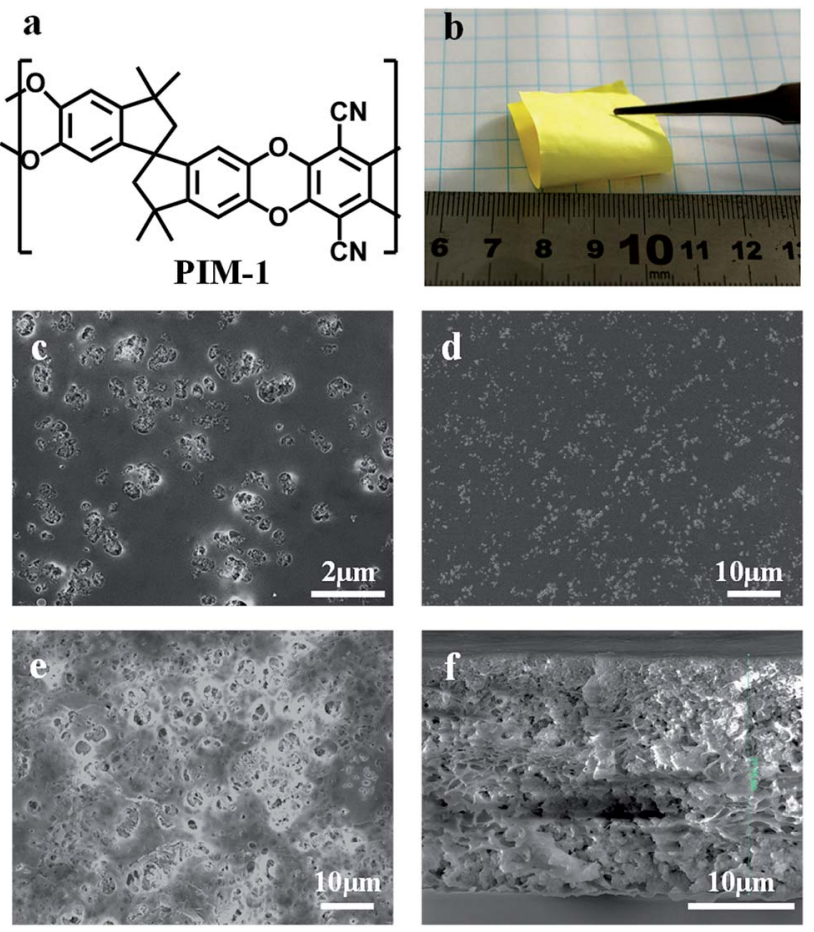

Fig. 1 (a) Chemical structure of PIM-1. (b) Photograph of a piece of the PIM-1/S separator. The SEM images of the PIM-1/S separator: ( $c$ and $d$ ) air-side surface, (e) bottom-side surface, and (f) cross-section.

a uniform distribution of macropores on both sides. The amplified SEM image of the membrane shows that the pore size is in the range of $0.5-1 \mu \mathrm{m}$ (Fig. 1c). $\mathrm{SiO}_{2}$ nanoparticles filling the pores were clearly observed in the form of aggregates. The existence of $\mathrm{SiO}_{2}$ in the composite membrane was also checked by X-ray diffraction (Fig. S4 $\dagger$ ). Fig. If shows the cross-sectional SEM image of the membrane. It shows a sponge-like structure with macropores distributed uniformly throughout the whole membrane. As a comparison, the PIM-1 membrane prepared from the doping solution without the addition of $n$-butyl alcohol and $\mathrm{SiO}_{2}$ nanoparticles exhibited a non-porous and dense structure (Fig. S5†).

To investigate the thermal stability of the PIM-1/S separator, a piece of it was heated to different temperatures in air. Meanwhile, a commercial PP separator was treated in the same way for comparison. As shown in Fig. 2a, the yellow PIM-1/S separator maintains its shape and colour well at all heating temperatures even when heated up to $300{ }^{\circ} \mathrm{C}$. In contrast, the commercial PP separator starts to curl at $120{ }^{\circ} \mathrm{C}$. It shrinks greatly above $120{ }^{\circ} \mathrm{C}$ and almost completely melts at $180{ }^{\circ} \mathrm{C}$. This result indicated that the thermal stability of the PIM-1/S separator was superior to that of the commercial PP separator. Fig. $2 \mathrm{~b}$ shows the differential scanning calorimetry (DSC) curves of the PIM-1/S and PP separators. The PIM-1/S separator displays a glass transition temperature above $300{ }^{\circ} \mathrm{C}$ and shows $5 \%$ weight loss above $500{ }^{\circ} \mathrm{C}$ (Fig. S6†). The DSC curve of the PP separator shows an endothermic peak at $130-180{ }^{\circ} \mathrm{C}$ and a melting point at $165^{\circ} \mathrm{C}$, which is consistent with previously reported results. ${ }^{33}$
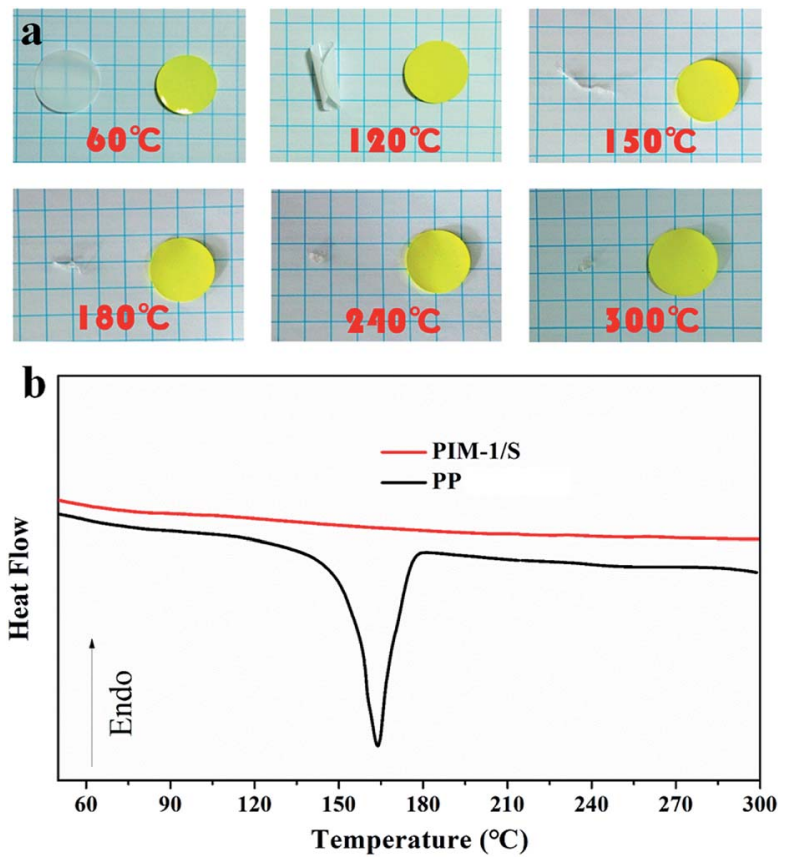

Fig. 2 (a) Photographs of PIM-1/S (yellow) and PP (white) separators after heating to various temperatures. (b) DSC curves of the separators.

Besides thermal stability, the wetting property of the separator towards a liquid electrolyte is another key factor for evaluating the separator performance. A separator with good electrolyte wetting capability can improve the electrochemical performance of a Li-ion battery. The electrolyte wettability of the PIM-1/S separator was investigated by dropping a droplet of the EMC/EC/DMC electrolyte on its surface. As shown in Fig. 3a, the electrolyte drop retains the shape of a liquid drop and can hardly diffuse on the PP separator. On the contrary, the electrolyte drop gets quickly absorbed by the PIM-1/S separator and spreads to the whole area. The electrolyte uptake of the PIM-1/S separator was $240 \%$, which was much higher than that of the PP separator $(110 \%)$ (Fig. 3b). On the one hand, the high electrolyte affinity and the uptake of the PIM-1/S separator can be ascribed to its sponge-like porous structure. On the other hand, the polar ether bonds existing in the dibenzodioxin linkage $(-\mathrm{O}-)$ and polar cyan group $(-\mathrm{CN})$ of PIM-1 are beneficial for enhancing the interaction between the electrolyte and the separator. The excellent wetting capability and high electrolyte uptake endow the PIM-1/S separator with improved Li-ion conductivity. The Liion conductivity of the PIM-1/S separator-based cell was $8.2 \times$ $10^{-4} \mathrm{~S} \mathrm{~cm}^{-1}$ at $25^{\circ} \mathrm{C}$, which was much higher than that of the commercial PP separator-based cell $\left(5.1 \times 10^{-4} \mathrm{~S} \mathrm{~cm}^{-1}, 25^{\circ} \mathrm{C}\right)$ (Table S1†).

To evaluate the electrochemical performance of the PIM-1/S separator, a series of electrochemical tests were performed. The electrochemical stability plays a crucial role in maintaining long-term charge-discharge reaction reversibility. We first investigated the linear sweep voltammetry behaviour of the PIM-1/S separator to examine its electrochemical stability. It showed that there were no obvious decomposition peaks below 


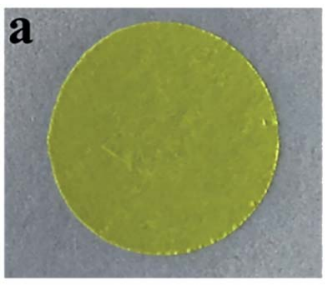

PIM-1 /S

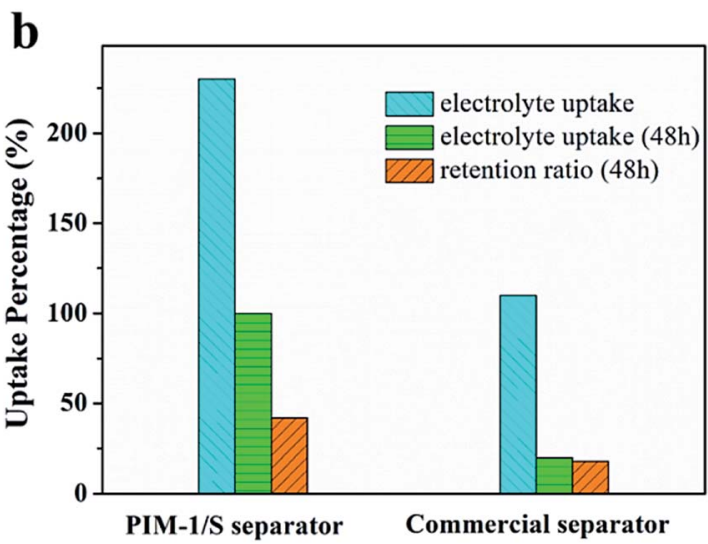

Fig. 3 (a) Photographs of the liquid electrolyte wetting behaviour of the two separators. (b) The electrolyte uptake and retention ratio of the separators.

$4.5 \mathrm{~V}\left(v s . \mathrm{Li}^{+} / \mathrm{Li}\right)$, which was similar to the observations for the PP separators, as shown in Fig. 4. This also demonstrated that the PIM-1/S separator was electrochemically stable and applicable for a Li-ion battery. The battery performance of the PIM-1/ $\mathrm{S}$ separator was further evaluated by using coin cells assembled with $\mathrm{LiFePO}_{4}$ cathode/separator/lithium anode, while the commercial PP separator was evaluated in the same way as a control experiment. Electrochemical impedance spectroscopy (EIS) was performed after assembling the cell. The Nyquist plot of the cell containing the PIM-1/S separator was similar to that of the cell containing the PP separator (Fig. S8 †).

Fig. 5a and $\mathrm{b}$ show the discharge capacity profiles of the two cells using PIM-1/S and PP as separators, respectively, cycled at various current rates. The initial discharge capacities of the

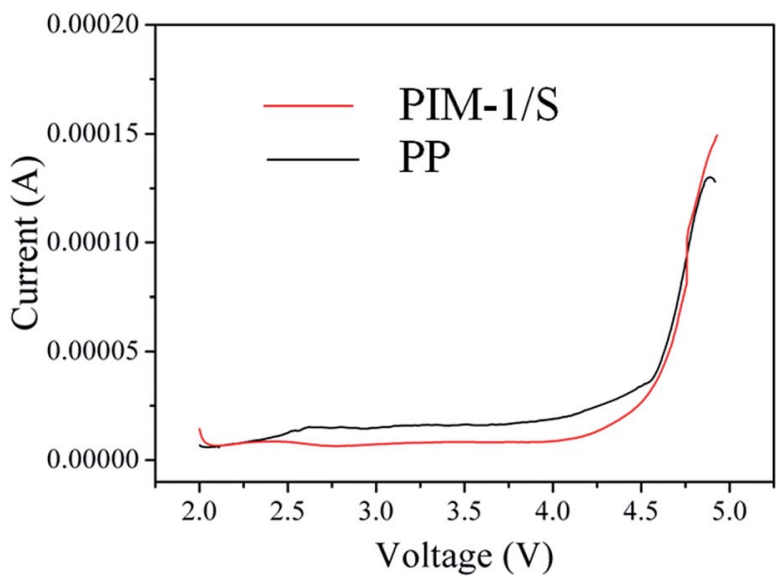

Fig. 4 Linear sweep voltammetry of PIM-1/S and PP separators.
PIM-1/S cell were 151.5, 125.4, 114.0, 105.0, 99.1 and $90.4 \mathrm{~mA} \mathrm{~h} \mathrm{~g}^{-1}$ at charge/discharge current rates of $0.1 \mathrm{C} / 0.1 \mathrm{C}$, $0.5 \mathrm{C} / 0.5 \mathrm{C}, 1 \mathrm{C} / 1 \mathrm{C}, 2 \mathrm{C} / 2 \mathrm{C}, 3 \mathrm{C} / 3 \mathrm{C}$, and $4 \mathrm{C} / 4 \mathrm{C}$, respectively; the values for the commercial PP separator were 143.7, 122.0, 110, 103.3, 96.5, and $85.1 \mathrm{~mA} \mathrm{~h} \mathrm{~g}^{-1}$ corresponding to the same current rates. It was obvious that the PIM- $1 / \mathrm{S}$ cell possessed higher initial discharge capacity than the PP cell at various current rates. The cycle performance of the cells at different current rates is summarized in Fig. 5c. The PIM-1/S cell still possessed higher discharge capacity than the PP separator cell in different current rate cycle processes. Moreover, the reversible discharge capacity for the PIM-1/S cell (from a high current rate to a low current rate) was also comparable to that of the PP separator. The electrochemical performance at a constant charge/discharge current rate (1C/1C) was further characterized to investigate the cycling performance (Fig. $5 \mathrm{~d}$ ). One cycle at $0.1 \mathrm{C} / 0.1 \mathrm{C}$ was used to activate the electrode material. The initial discharge capacity at $1 \mathrm{C} / 1 \mathrm{C}$ was $117 \mathrm{~mA} \mathrm{~h} \mathrm{~g}^{-1}$ for the PIM-1/S cell, while its value was $115 \mathrm{~mA} \mathrm{~h} \mathrm{~g}^{-1}$ for the PP cell. After 100 cycles, the discharge capacity of the PIM-1/S cell was $110 \mathrm{~mA} \mathrm{~h} \mathrm{~g}^{-1}$ and that of the PP cell was $101 \mathrm{~mA} \mathrm{~h} \mathrm{~g}^{-1}$. The PIM$1 / \mathrm{S}$ cell displayed a higher capacity retention rate $(94 \%)$ than the PP cell (88\%), indicating a more stable charge/discharge behaviour. The improvement in the electrochemical performance of the PIM-1/S separator corresponding to various current rate cycling and long-time cycling at a constant current rate was ascribed to the interconnected porous structure and
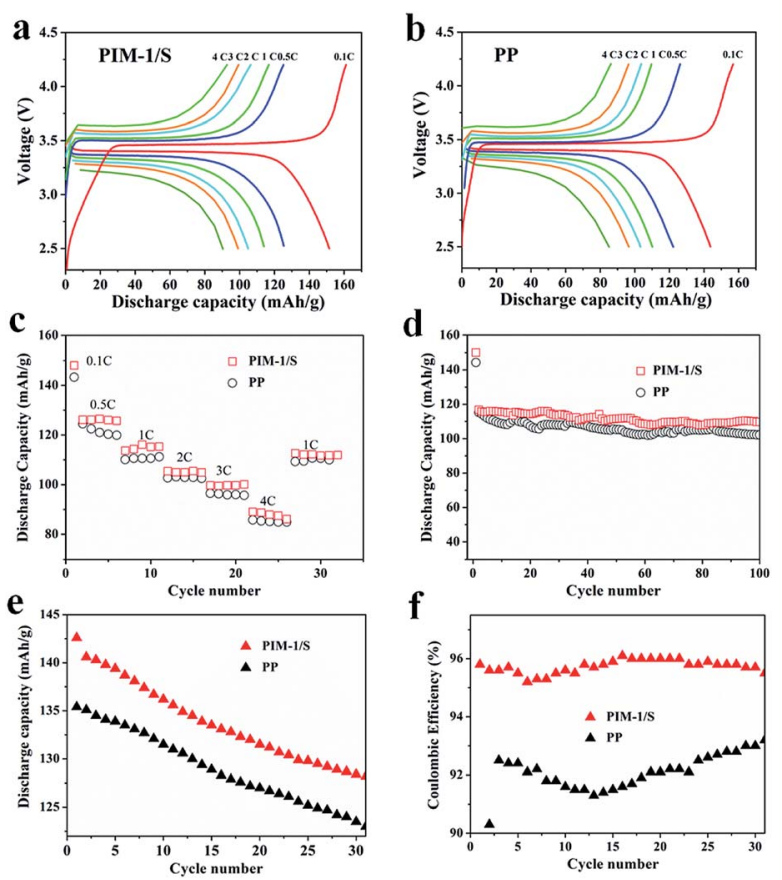

Fig. 5 Voltage profiles of (a) PIM-1/S and (b) PP cells cycled at various current rates from 0.1 to $4 \mathrm{C}$. Discharge capacity of the two cells at different current rates. (c) Discharge capacity at various current rates. (d) Discharge capacity over 100 cycles at $1 \mathrm{C} / 1 \mathrm{C}$ charge/discharge current rate at room temperature. Discharge capacity (e) and coulombic efficiency (f) over 30 cycles at $1 \mathrm{C} / 1 \mathrm{C}$ charge/discharge current rate at $60^{\circ} \mathrm{C}$. 
the stable polymer chemical structure; this was beneficial for $\mathrm{Li}^{+}$ ion transport and electrolyte uptake as well as in reducing the side reactions during the cycling process.

The cycle performance of the two cells at a high temperature $\left(60{ }^{\circ} \mathrm{C}\right)$ was also evaluated at $1 \mathrm{C}$ rate. In 30 cycles, the discharge capacity of the PIM-1/S cell decreased from $143.5 \mathrm{~mA} \mathrm{~h} \mathrm{~g}^{-1}$ to $128.7 \mathrm{~mA} \mathrm{~h} \mathrm{~g}^{-1}$, while the discharge capacity of the PP cell decreased from $135.5 \mathrm{~mA} \mathrm{~h} \mathrm{~g}^{-1}$ to $123.0 \mathrm{~mA} \mathrm{~h} \mathrm{~g}^{-1}$ (Fig. 5e). The coulombic efficiency of the PIM-1/S separator was in the range of 95-96\%, which was obviously higher than that of the PP cell (91-93\%) (Fig. 5f). This result further demonstrates that the $\mathrm{PIM}-1 / \mathrm{S}$ cell is more suitable for running at a high temperature than the PP cell due to its high thermal stability and better Liion conductivity.

\section{Conclusions}

In conclusion, a sponge-like Li-ion battery separator derived from PIM-1 was successfully fabricated using a nanoparticleassisted phase transition method. The PIM-1/S separator showed good thermal resistance, high electrolyte uptake, and excellent $\mathrm{Li}$-ion conductivity of the cell. The $\mathrm{LiFeO}_{4} / \mathrm{Li}$ cell by using the PIM-1/S separator showed good cycle and rate performances and simultaneously demonstrated better chargedischarge performance than the cell using the commercial PP separator at a high temperature. The PIM-1-based separator exhibited great potential in a high-power Li-ion battery. Thus, our work provides a new route for designing and selecting new types of separators to meet the requirements of high-power Liion batteries.

\section{Conflicts of interest}

There are no conflicts of interest to declare.

\section{Acknowledgements}

This work was financially supported by the National Natural Science Funds for Distinguished Young Scholar (51625306), the Key Project of National Natural Science Foundation of China (21433021), the National Natural Science Foundation of China (51803145), the Project funded by China Postdoctoral Science Foundation (2018M630598), and Joint Research Fund for Overseas Chinese, Hong Kong and Macao Scholars (21728602).

\section{Notes and references}

1 J.-M. Tarascon and M. Armand, Nature, 2001, 414, 359.

2 J.-M. T. M. Armand, Nature, 2008, 451, 652.

3 M. Rosa Palacín, Chem. Soc. Rev., 2009, 38, 2565.

4 J. Hassoun and S. Bruno, Adv. Mater., 2010, 22, 5198.

5 X. Huang and J. Hitt, J. Membr. Sci., 2013, 425, 163-168.

6 H. Lee, M. Yanilmaz, O. Toprakci, K. Fu and X. Zhang, Energy

Environ. Sci., 2014, 7, 3857.
7 W. Lu, Z. Yuan, Y. Zhao, H. Zhang, H. Zhang and X. Li, Chem. Soc. Rev., 2017, 46, 2199.

8 H. R. Jung, D. H. Ju, W. J. Lee, X. Zhang and R. Kotek, Electrochim. Acta, 2009, 54, 3630.

9 X. S. Huang, J. Solid State Electrochem., 2011, 15, 649.

10 J. Zhang, Z. Liu, Q. Kong, C. Zhang, S. Pang, L. Yue, X. Wang, J. Yao and G. Cui, ACS Appl. Mater. Interfaces, 2013, 5, 128134.

11 J.-J. Woo, Z. Zhang, N. L. Dietz Rago, W. Lu and K. Amine, J. Mater. Chem. A, 2013, 1, 8538.

12 P. Arora and Z. Zhang, Chem. Rev., 2004, 104, 4419-4462.

13 R. E. Gerver and J. P. Meyers, J. Electrochem. Soc., 2011, 158, 835.

14 C. J. Orendorff, T. N. Lambert, C. A. Chavez, M. Bencomo and K. R. Fenton, Adv. Energy Mater., 2013, 3, 314.

15 M.-H. Ryou, Y. M. Lee, J.-K. Park and J. W. Choi, Adv. Mater., 2011, 23, 3066.

16 C. M. Costa, M. M. Silvab and S. Lanceros-Me'ndez, RSC Adv., 2013, 3, 11404.

17 J.-Y. Sohn, J.-S. Im, J. Shin and Y.-C. Nho, J. Solid State Electrochem., 2012, 16, 551.

18 W. Jiang, Z. H. Liu, Q. S. Kong, J. H. Yao, C. J. Zhang, P. X. Han and G. L. Cui, Solid State Ionics, 2013, 232, 44.

19 M. Kim and J. H. Park, Adv. Energy Mater., 2013, 3, 1417.

20 M. Baginska, B. J. Blaiszik, R. J. Merriman, N. R. Sottos, J. S. Moore and S. R. White, Adv. Energy Mater., 2012, 2, 583.

21 J. Shi, Y. Xia, Z. Yuan, H. Hu, X. Li, H. Zhang and Z. Liu, Sci. Rep., 2015, 5, 8255.

22 X. Huang, J. Power Sources, 2012, 216, 216.

23 M. J. Lee, J. H. Kim, H.-S. Lim, S. Y. Lee, H. K. Yu, J. H. Kim, J. S. Lee, Y.-K. Sun, Mi. D. Guiver, K. D. Suh and Y. M. Lee, Chem. Commun., 2015, 51, 2068.

24 P. M. Budd, E. S. Elabas, B. S. Ghanem, S. Makhseed, N. B. McKeown, B. Msayib, C. E. Tattershall and D. Wang, Adv. Mater., 2004, 16, 456.

25 N. B. McKeown and P. M. Budd, Chem. Soc. Rev., 2006, 35, 675.

26 X. Weng, J. E. Baez, M. Khiterer, M. Y. Hoe, Z. Bao and K. J. Shea, Angew. Chem., Int. Ed., 2015, 54, 11214.

27 T. S. Anokhinaa, A. A. Yushkina, P. M. Buddb and A. V. Volkov, Sep. Purif. Technol., 2015, 156, 683.

28 P. Gorgojo, S. Karan, H. C. Wong, M. F. Jimenez-Solomon, J. T. Cabral and A. G. Livingston, Adv. Funct. Mater., 2014, 24, 4729.

29 C. Li, A. L. Ward, S. E. Doris, T. A. Pascal, D. Prendergast and B. A. Helms, Nano Lett., 2015, 15, 5724.

30 Z. Wang, X. Liu, D. Wang and J. Jin, Polym. Chem., 2014, 5, 2793.

31 X. S. Huang, J. Solid State Electrochem., 2011, 15, 649.

32 J.-J. Woo, Z. Zhang, N. L. Dietz Rago, W. Lu and K. Amine, J. Mater. Chem. A, 2013, 1, 8538.

33 W. Zhang, Z. Tu, J. Qian, S. Choudhury, L. A. Archer and Y. Lu, Small, 2018, 14, 1703001. 